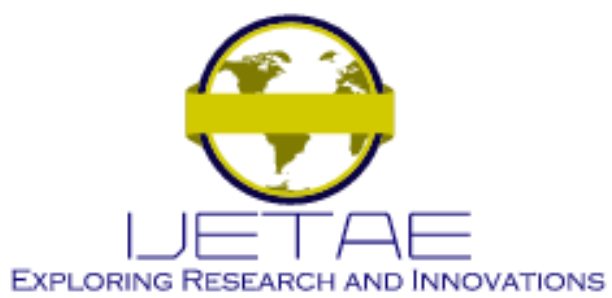

International Journal of Emerging Technology and Advanced Engineering

Website: www.ijetae.com (E-ISSN 2250-2459, Scopus Indexed, ISO 9001:2008 Certified Journal, Volume 12, Issue 01, January 2022)

\title{
Performance Evaluation of Regression Analysis Algorithms in Predicting the Enrollment of Basic Education
}

\author{
Elizalde L. Piol ${ }^{1}$, Luisito Lolong Lacatan ${ }^{2}$, Jaime P. Pulumbarit ${ }^{3}$ \\ ${ }^{I}$ Department of Education \& AMA University, Philippines \\ ${ }^{2}$ College of Engineering, Laguna University \\ ${ }^{3}$ Bulacan State University, Malolos Bulacan
}

\begin{abstract}
The use of Linear Regression in predicting enrolment has been shown to be beneficial, although it varies with various datasets and attributes; varying weights of the correlation of the attributes can be discarded if they do not impact the prediction. Data collecting had grown since prior investigations, resulting in a more complicated dataset with many varieties. As a result of the data being created by multiple clerks, cleaning and combining proved tough; nonetheless, the fundamental parameters remain intact. Different algorithms were examined but Linear Regression obtained the highest accuracy with a $\mathbf{1 2 . 3 9 8}$ percentage for the absolute error and a root mean squared of 26.936 to create a tangible model to anticipate the enrolment of Region IVA CALABARZON in the Philippines. This demonstrates that it was 2.067 percentage points more than the prior research.
\end{abstract}

\section{INTRODUCTION}

During the Covid19 epidemic, public and private schools in the Philippines implemented Learning Modality (LM). The Department of Education (DepEd) created a television learning style to encourage assistance in the module type approach in order to retain learners' interest and willingness to continue their studies [1], [2]. However, some of the students do not have access to the program since they do not own televisions. As a result, the distribution and support of instructors in completing the work per topic has become challenging owing to the country's access to the internet, particularly in the country's metropolitan and isolated locations [3], [4].

The simplest way to deal with the learners is to offer them with learning materials that parents can help the learners answer. The printed modules'(PM) dilemma is dependent on student enrolment, which is subsidized by the government [5]. The enrollment expectation had not been forecast, which means that the materials have no accurate statistics and rely only on when the learners registered in the school.
One of the problems is that particular locations produce too much or too little PM, resulting in a shortage of bond sheets and ink for printers and photocopiers [6] [7] . There are also delays in PM production owing to gathering the number of registrants first before production, which results in late learning weeks of planned instruction delivery. Various techniques were used to test the new system, however the test resulted in more issues [8], [9].

To tackle this problem, the correct prediction technique must be found, which relates the prior grade to the future grade or averaging the data from the previous data to get the new forecast. However, population growth accelerates at a pace of six times the rate of inflation [10]. To fix this problem, we might take the most recent number of registrants and multiply it by the inflation rate of six. This may alleviate a problem, but there are a number of other difficulties, such as changing addresses due to causes such as job, returning to hometown, and others, that would be additional considerations in estimating the number of enrollees [11].

Forecasting methods include linear regression, deep learning, decision trees, gradient boosted trees, random forests, and support vector machines [12], [13]. The goal of this study is to anticipate the number of primary school enrollment in Batangas City and the rest of Batangas Province using several algorithms and to suggest the best performance analysis. The study's findings would serve as the foundation for LM production in the province. Though none of the methods achieve a complete degree of accuracy, the substantial value reduces the percentage error for LM printing.

\section{DATA PREPARATION}

The municipalities of Batangas City, and the province of Batangas has been the highest population in terms of students in the primary school. 


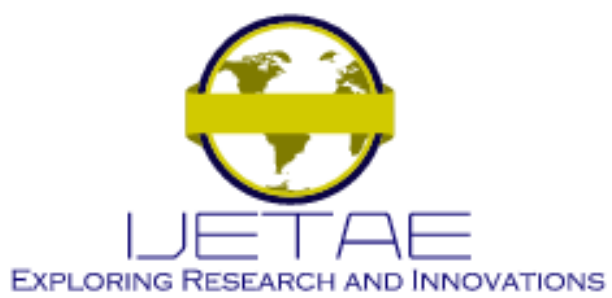

International Journal of Emerging Technology and Advanced Engineering

Website: www.ijetae.com (E-ISSN 2250-2459, Scopus Indexed, ISO 9001:2008 Certified Journal, Volume 12, Issue 01, January 2022)

The data was gathered through the DepEd division office of Batangas City, Philippines. The data was presented contains parameters of grade level, name of school, gender and year of the academic year [14], [15], [16].

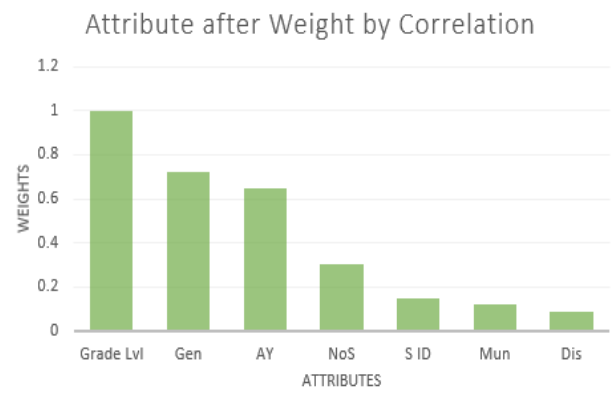

Figure 1. Weight by correlation

To prepare the data, data cleansing was performed. Figure 1 shows that, using the weight by correlation technique, other parameters that would have no influence on the prediction, such as school ID, town, and district, are removed. The second step is to assign the quantity of data to certain rows based on the criteria you've selected. Third, a replacement or averaging procedure was used to check the data for null values. The following stage is deduplication, which removes any duplicate values[17] $\backslash$. In any field, there must be no duplicate values. Following that is verification, which checks the data to determine if the values from the source data are legitimate, and lastly importation, which prepares the data for all of the algorithms.

The combined data yielded 29,038 items, which were separated into two groups: the training dataset and the testing dataset. 70 percent for training and 30 percent for testing, which will be used to judge the model's performance. The linear regression model with the lowest absolute value was 14.465 and a dataset of 3,445 rows. As the dataset size grows, the linear regression will be examined to see if it achieves a lower or greater accuracy.

\section{METHODS}

The technique for evaluating the linear regression model will be carried out in stages [18]. The first stage is data collection, the dataset was collated and merged with different dataset within the region. Next is data cleaning, preparing the data and converting it to a binomial datatype compatible with linear regression. This step also covers deduplication, replacement and verification.
Next is splitting the dataset to two parts which includes having a training and testing dataset. Next is training the dataset, this process involved linear regression algorithm. The creation of model and testing the performance in the dataset will be the last stage. As a result, the dataset will be evaluated with multiple algorithms to see whether the model is the best match for the dataset [19]. The comparison will also display each process's distinct topologies, relative error, standard deviation, training time, and testing time [20].

The enrollment statistics from 2017-2020 were filtered and aggregated from the data acquired in different sections of Region IVA CALABARZON of the Philippines to build a larger dataset from the previous study.

The use of data cleaning improved the dataset's quality by picking the appropriate characteristics using correlation, deleting duplicate entries, and managing data. The end result will be a prepared dataset suitable for linear regression training and testing.

20,326 population would run under training for formulation of the model, while the remaining 8,712 will be evaluating the model for the performance [21]. While the relative error will define the difference of the accuracy, other attributes will be considered. The time performance of the training and testing the linear regression that was used in the study[22].

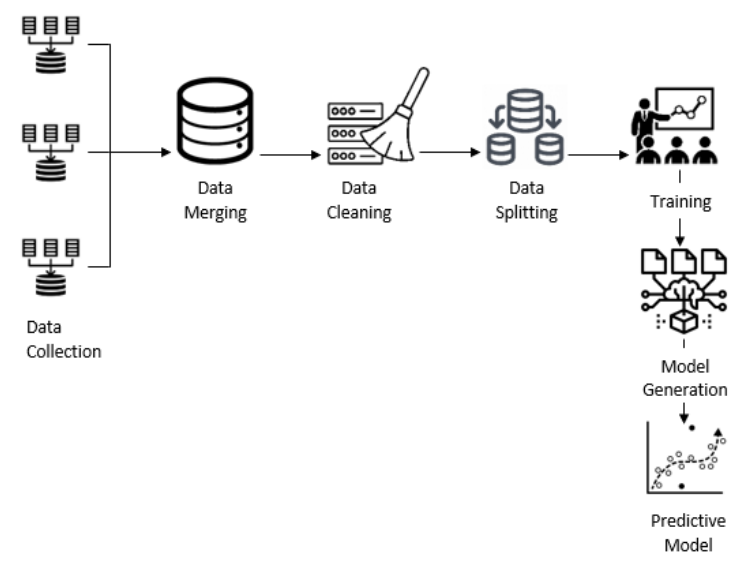

Figure 2. Methodology

A comparative study on the different algorithms using the same dataset will be used in Decision Tree, Deep Learning[23], Random Forest, Gradient Boosted Tree and Support Vector Machine. 


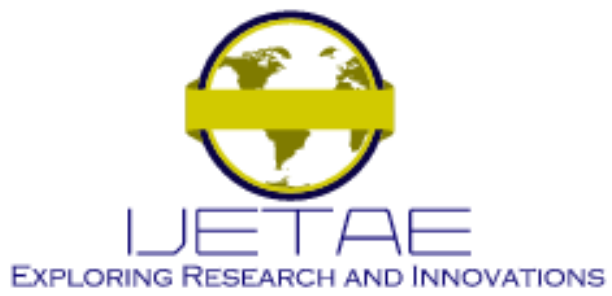

International Journal of Emerging Technology and Advanced Engineering

Website: www.ijetae.com (E-ISSN 2250-2459, Scopus Indexed, ISO 9001:2008 Certified Journal, Volume 12, Issue 01, January 2022)

Most algorithms do not fit a specific dataset, which is why selecting the right method for each dataset is critical[24]. Some of the predictive algorithms only results into a binomial result which are 1 or 0 , true or false and yes or no, but some have multiple output which are called multivariate results which are person, cat, dog. In this state, the usage of different algorithms would consider the prediction output. Thus, calculating method is based on the variable setting and coefficient state[25]. where the dependent variables are considered and see how much this column may affect the prediction result, moreover, the independent variables may be disregarded during the prediction since it has indirect relevance to the prediction. The computation of the regression analysis is reliant on the dependent and independent variables, as stated in the formula below.

Formula

$$
Y_{i}=f\left(X_{i}, \beta\right)+e_{i}
$$

$Y_{i}=$ dependent variable

$f=$ function

$X_{i}=$ independent variable

$\beta=$ unknown parameters

$e_{i}=$ error terms

By suiting a linear equation to experimental data, linear regression seeks to model the joining between two variables[26][27]. a variable is regarded as an explanatory variable, while the other is regarded as a dependent variable. A modeler, for example, could wish to use a linear regression model to match people's weights to their heights.

\section{Result And Discussion}

The major property of linear regression is to calculate all parameters with the given weight corresponding to the coefficient and the standard coefficient based on the enrollment data for the [28] forecasting of the enrollees for the Region 4A for the school year 2022-2023. The preparation would lead to a close number of learning material to printed allocated for both elementary and high school students within the area. [2]

Table 1 displays the coefficient for each of the attribute items. Detailing the criteria will show that various levels have an impact on the region's enrolment population.
Table 1.

Linear Regression Coefficient

\begin{tabular}{lc}
\hline Attributes & Coefficient \\
\hline Level.grade1 & -0.148 \\
Level.grade2 & 4.5 \\
Level.grade3 & 0.145 \\
Level.grade4 & -0.522 \\
Level.grade5 & 1.192 \\
Level.grade6 & 2.068 \\
Level.grade7 & 1.289 \\
Level.grade8 & 3.005 \\
Level.grade9 & -0.117 \\
Level.grade10 & 2.358 \\
Gender.Male & -1.814 \\
Gender.Female & 0.456 \\
Year & -0.308 \\
\hline
\end{tabular}

When two qualities are combined, it is notable that there are few examples of the coeficient heading towards the positive note. This is seen in the diagram below.

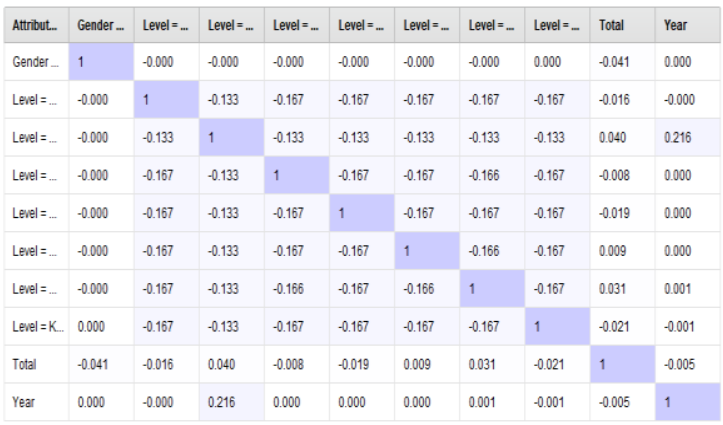

Figure 3. Correlation of the attributes

The integration of the variables shows that the gearing is pointing in the other direction, as seen in figure 3. In other cases, the traits contradict each other in such a way that when one grows, the other diminishes.

Table 2.

Comparative Results

\begin{tabular}{|c|c|c|c|c|}
\hline Model & $\begin{array}{l}\text { Root Mean } \\
\text { Squared Error }\end{array}$ & $\begin{array}{l}\text { Absolute } \\
\text { Error (\%) }\end{array}$ & $\begin{array}{l}\text { Training Time } \\
\text { (milliseconds) }\end{array}$ & $\begin{array}{l}\text { Scoring Time } \\
\text { (milliseconds) }\end{array}$ \\
\hline Decision Tree & 27.119 & $\begin{array}{l}17.289 \\
17.267\end{array}$ & $\sim 0$ & $\begin{array}{l}1 \\
1\end{array}$ \\
\hline $\begin{array}{l}\text { Random Forest } \\
\text { Gradient } \\
\text { Boosted Tree }\end{array}$ & $\begin{array}{c}27.12 \\
27.048\end{array}$ & $\begin{array}{l}17.267 \\
17.078\end{array}$ & $\begin{array}{c}1 \\
34\end{array}$ & $\begin{array}{c}1 \\
10\end{array}$ \\
\hline $\begin{array}{l}\text { Support Vector } \\
\text { Machine }\end{array}$ & 28.116 & 15.701 & 12000 & 716 \\
\hline Deep Learning & 27.031 & 17.129 & 445 & 40 \\
\hline $\begin{array}{l}\text { Linear } \\
\text { Regression }\end{array}$ & 26.963 & 12.398 & 5 & 3 \\
\hline
\end{tabular}




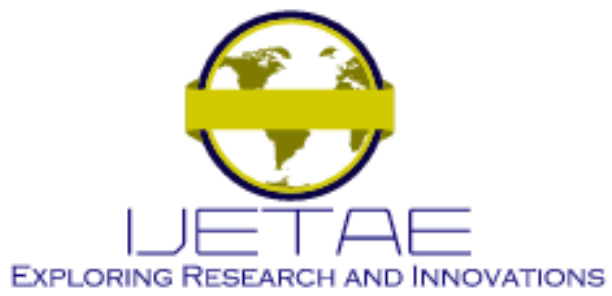

International Journal of Emerging Technology and Advanced Engineering Website: www.ijetae.com (E-ISSN 2250-2459, Scopus Indexed, ISO 9001:2008 Certified Journal, Volume 12, Issue 01, January 2022)

Using different algorithms with the same dataset, the following results had been shown in the table 2 . With an evident result of 26.963 for the root mean square of the linear regression and a 12.398 percentage for the absolute error. The difference of each algorithm is close but the linear regression is still the best model for the dataset used for enrollment prediction. While the decision tree offers the best performance in training and testing time, the performance of accuracy is still the factor to consider.

\section{CONCLUSION}

Based on the results, the real implementation may have a linear regression accuracy of 87.602 percent. The timing may be delayed or varied by milliseconds, but the performance must be considered. A 3.303 percent difference in support vector system with the same dataset and a 2.067 percent difference from the prior research. As a result, the model becomes more efficient as the dataset's richness increases.

\section{REFERENCES}

[1] E. Jimenez and Y. Sawada, "Public for private: The relationship between public and private school enrollment in the Philippines," Econ. Educ. Rev., vol. 20, no. 4, pp. 389-399, 2001, doi: 10.1016/S0272-7757(00)00061-3

[2] E. L. Piol, L. L. Lacatan, and J. P. Pulumbarit, "Predictive Analysis of the Enrolment of Elementary Schools Using Regression Algorithms," Int. J. Emerg. Technol. Adv. Eng., vol. 11, no. 11, pp. 184-188, 2021, doi: 10.46338/ijetae1121.

[3] M. A. Dela Cruz, "The Effectiveness of Information Systems in the Enrollment of State Universities and Colleges in Central Luzon Philippines : A Basis for Enhancement," Iba, 2019.

[4] J. N. Mindoro, N. U. Pilueta, Y. D. Austria, L. Lolong Lacatan, and R. M. Dellosa, "Capturing Students' Attention through Visible Behavior: A Prediction Utilizing YOLOv3 Approach," 2020 11th IEEE Control Syst. Grad. Res. Colloquium, ICSGRC 2020 - Proc., no. August, pp. 328-333, 2020, doi: 10.1109/ICSGRC49013.2020.9232659.

[5] R. V. Nuncio, M. M. Arcinas, R. I. G. Lucas, J. V. Q. Alontaga, S. G. T. Neri, and J. M. Carpena, "An E-learning outreach program for public schools: Findings and lessons learned based on a pilot program in Makati City and Cabuyao City, Laguna, Philippines," Eval. Program Plann., vol. 82, no. May, p. 101846, 2020, doi: 10.1016/j.evalprogplan.2020.101846.

[6] H. Karal, M. Kokoc, and L. Silbir, "Problems Encountered by Distance Education Students in Online Test Module: A Case Study From the Distance Education Research and Application Center, Karadeniz Technical University, Turkey.," US-China Educ. Rev. A, vol. 6, pp. 768-773, 2011.

[7] S. J. R. Manglapuz and L. L. Lacatan, "Academic management android application for student performance analytics: A comprehensive evaluation using ISO 25010:2011," Int. J. Innov. Technol. Explor. Eng., vol. 8, no. 12, pp. 5085-5089, 2019, doi: 10.35940/ijitee.L2735.1081219.
[8] M. D. Hernandez, A. C. Fajardo, and R. P. Medina, "A hybrid convolutional neural network-gradient boosted classifier for vehicle classification,” Int. J. Recent Technol. Eng., vol. 8, no. 2, pp. 213216, 2019, doi: 10.35940/ijrte.B1016.078219.

[9] L. Lacatan, "Success of Hybrid Method to an e-Community of Learners in Cyberspace," Proc. Appl. Int. Bus. Conf. 2008 SHORTTERM, pp. 381-384, 2008.

[10] J. N. Rutherford, A. deMartelly Victoria, H. B. Ragsdale, J. L. Avila, N. R. Lee, and C. W. Kuzawa, "Global population variation in placental size and structure: Evidence from Cebu, Philippines," Placenta, vol. 85, no. March, pp. 40-48, 2019, doi: 10.1016/j.placenta.2019.08.076.

[11] M. B. B. Chavez and L. Q. Tadena, "Alternative Learning System in Time of COVID-19 Pandemic: Philippine Context," 14th La Salle Univ. Arts Congr., vol. 5, 2021, [Online]. Available: https://www.dlsu.edu.ph/wp-content/uploads/pdf/conferences/artscongress-proceedings/2021/sldp-03.pdf.

[12] A. S. Alon, M. C. A. Venal, S. V. Militante, M. D. Hernandez, and H. B. Acla, "Lyco-frequency: A development of lycopersicon esculentum fruit classification for tomato catsup production using frequency sensing effect," Int. J. Adv. Trends Comput. Sci. Eng., vol. 9, no. 4, pp. 4690-4695, 2020, doi: 10.30534/ijatcse/2020/72942020.

[13] M. D. Hernandez, A. C. Fajardo, R. P. Medina, J. T. Hernandez, and R. M. Dellosa, "Implementation of data augmentation in convolutional neural network and gradient boosted classifier for vehicle classification," Int. J. Sci. Technol. Res., vol. 8, no. 12, pp. 185-189, 2019.

[14] M. M. Shahabadi and M. Uplane, "Synchronous and Asynchronous e-learning Styles and Academic Performance of e-learners," Procedia - Soc. Behav. Sci., vol. 176, pp. 129-138, 2015, doi: 10.1016/j.sbspro.2015.01.453.

[15] M. Chamilco, A. Pacheco, C. Peñaranda, E. Felix, and M. Ruiz, "Materials and methods on digital enrollment system for educational institutions," Mater. Today Proc., no. xxxx, pp. 2-6, 2021, doi: 10.1016/j.matpr.2021.04.213.

[16] L. L. Lacatan, "Hybrid Method and Face to Face Method in Teaching Mathematics : Effects on Students 'Performance," vol. 3, no. 2, pp. 143-146, 2013, doi: 10.7763/IJIET.2013.V3.252.

[17] A. H. Ansari, "Collaboration or competition? Evaluating the impact of Public Private Partnerships (PPPs) on public school enrolment," Int. J. Educ. Res., vol. 107, no. February, p. 101745, 2021, doi: 10.1016/j.ijer.2021.101745.

[18] N. K. Biswas, S. Banerjee, U. Biswas, and U. Ghosh, "An approach towards development of new linear regression prediction model for reduced energy consumption and SLA violation in the domain of green cloud computing," Sustain. Energy Technol. Assessments, vol. 45, no. February, p. 101087, 2021, doi: 10.1016/j.seta.2021.101087.

[19] A. Bender et al., "Dataset for multidimensional assessment to incentivise decentralised energy investments in Sub-Saharan Africa," Data Br., vol. 37, p. 107265, 2021, doi: 10.1016/j.dib.2021.107265.

[20] R. Bozick, D. M. Anderson, and L. Daugherty, "Patterns and predictors of postsecondary re-enrollment in the acquisition of stackable credentials," Soc. Sci. Res., vol. 98, no. April 2020, p. 102573, 2021, doi: 10.1016/j.ssresearch.2021.102573. 


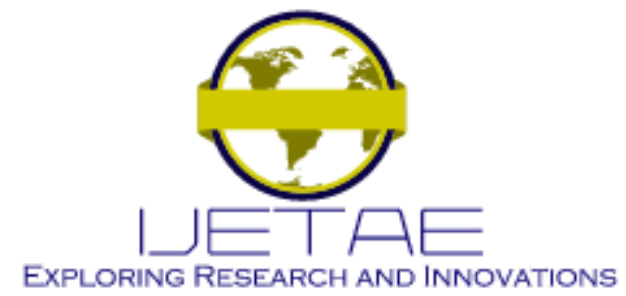

International Journal of Emerging Technology and Advanced Engineering

Website: www.ijetae.com (E-ISSN 2250-2459, Scopus Indexed, ISO 9001:2008 Certified Journal, Volume 12, Issue 01, January 2022)

[21] S. Guak, K. Kim, W. Yang, S. Won, H. Lee, and K. Lee, "Prediction models using outdoor environmental data for real-time PM10 concentrations in daycare centers, kindergartens, and elementary schools," Build. Environ., vol. 187, no. October 2020, p. 107371, 2021, doi: 10.1016/j.buildenv.2020.107371.

[22] G. Ciulla and A. D'Amico, "Building energy performance forecasting: A multiple linear regression approach," Appl. Energy, vol. 253, no. April, p. 113500, 2019, doi: 10.1016/j.apenergy.2019.113500.

[23] Z. Sarafraz, H. Sarafraz, M. Sayeh, and J. Nicklow, "Student Yield Maximization Using Genetic Algorithm on a Predictive Enrollment Neural Network Model,” Procedia Comput. Sci., vol. 61, pp. 341348, 2015, doi: 10.1016/j.procs.2015.09.154.

[24] I. Ilic, B. Görgülü, M. Cevik, and M. G. Baydoğan, "Explainable boosted linear regression for time series forecasting," Pattern Recognit., vol. 120, 2021, doi: 10.1016/j.patcog.2021.108144.
[25] Y. Yin, "Model-free tests for series correlation in multivariate linear regression," J. Stat. Plan. Inference, vol. 206, no. xxxx, pp. 179-195, 2020, doi: 10.1016/j.jspi.2019.09.011.

[26] R. Strietholt, N. Hogrebe, and H. D. Zachrisson, "Do increases in national-level preschool enrollment increase student achievement? Evidence from international assessments," Int. J. Educ. Dev., vol. 79, no. October, p. 102287, 2020, doi: 10.1016/j.ijedudev.2020.102287.

[27] D. Biancardi and M. Bratti, "The effect of introducing a Research Evaluation Exercise on student enrolment: Evidence from Italy," Econ. Educ. Rev., vol. 69, no. November 2018, pp. 73-93, 2019, doi: 10.1016/j.econedurev.2019.01.001.

[28] L. L. Lacatan and G. M. Penuliar, "Competency-Based Mapping Tool in Personnel Management System using Analytical Hierarchy Process," 4th Int. Conf. Mach. Learn. Mach. Intell., 2021, doi: $10.1145 / 3490725.3490734$. 